\title{
BMJ Open Relationship between use of general practice and healthcare costs at the end of life: a data linkage study in New South Wales, Australia
}

\author{
Bich Tran, ${ }^{1}$ Michael O Falster, ${ }^{1}$ Federico Girosi, ${ }^{2}$ Louisa Jorm ${ }^{1}$
}

To cite: Tran B, Falster MO, Girosi F, et al. Relationship between use of general practice and healthcare costs at the end of life: a data linkage study in New South Wales, Australia. BMJ Open 2016;6:e009410.

doi:10.1136/bmjopen-2015009410

- Prepublication history and additional material is available. To view please visit the journal (http://dx.doi.org/ 10.1136/bmjopen-2015009410).

Received 16 July 2015 Revised 17 November 2015 Accepted 18 November 2015

\section{CrossMark}

${ }^{1}$ Centre for Big Data Research in Health, UNSW Australia, Kensington, New South Wales, Australia

${ }^{2}$ Centre for Health Research, School of Medicine, Western Sydney University, Campbelltown, New South Wales, Australia

Correspondence to Dr Bich Tran; bich.tran@unsw.edu.au

\section{ABSTRACT}

Objective: This analysis investigated the relationships between healthcare expenditures in the last 6 months of life and use of general practitioner (GP) services in the preceding 12-month period among older residents of New South Wales, Australia.

Methods: Questionnaire data (2006-2009) for more than 260000 people aged 45 years and over were linked to individual hospital and death records and cost data. For 14819 participants who died during followup, generalised linear mixed models were used to explore the relationships between costs of hospital, emergency department (ED) and Medicare-funded outpatient and pharmaceutical services in the last 6 months of life, and quintile of GP use in the 187 months before death. Analyses were adjusted for age at death, sex, educational level, language, private health insurance, household income, self-reported health status, functional limitation, psychological distress, number of comorbidities and geographic clustering.

Results: Almost $85 \%$ of decedents had at least one hospitalisation in the last 6 months, and the mean (median) of total cost for each person in this period was \$A20 453 (14 835). There was no significant difference in the hospital cost, including cost for preventable hospitalisations in the last 6 months of life, across quintiles of GP use in the 18-7 months before death. Participants in the lowest quintile of GP use incurred more ED costs, but ED costs were similar across the other quintiles of GP use. Costs for Medicare-funded outpatient services and pharmaceuticals increased steeply according to quintile of GP use.

Conclusions: In the Australian setting, there was no association between use of GP services in the 18-7 months before death and hospital costs in the last 6 months, but there was significant association with higher costs for outpatient services and pharmaceuticals. However, there was some indication that limited GP access might be associated with increased ED use at end of life.

\section{INTRODUCTION}

The costs of healthcare rise dramatically at the end of life, especially in developed

\section{Strengths and limitations of this study}

- This is a large-scale study to explore the longitudinal relationship between use of primary services and healthcare expenditures at the end of life, using detailed individual-level information about potential confounders and health service use.

- This study includes costs for inpatient, emergency department, outpatient services and pharmaceuticals.

- Limitations include the use of administrative claims data containing only limited information about quality of primary care services and cause of death. The use of self-reported data for covariates at baseline may also introduce some bias.

countries. ${ }^{1}{ }^{2}$ Most of these costs are spent caring for older people, such that in Australia almost $9 \%$ of total hospital expenditure is attributable to care for people aged 65 years and over in their last year of life, which is estimated to be about $5 \%$ of the total health budget. $^{3}$ These high costs could at least, in part, reflect unnecessary and expensive treatments for those at the end of life. ${ }^{4}$

The high costs of healthcare at the end of life have focused attention on how these costs might be contained, with better end-of-life care delivered, through provision of primary, community and palliative care services. ${ }^{5}$ However, little information exists about the potential to reduce end-of-life costs through better management in primary care in the lead-up to end of life. A study of almost 80000 deceased Medicare beneficiaries aged 66 years and over in the USA found that greater numbers of visits to primary care physicians in the year prior to the 6-month end-of-life period were associated with lower total healthcare costs at the end of life, and with fewer preventable hospitalisations for congestive heart failure and chronic 
obstructive pulmonary disease. ${ }^{6}$ The applicability of these findings to a country such as Australia, where the government provides universal health coverage for its citizens and there is no charge for treatment at public hospitals, is unknown.

In a system with greater access to publically funded healthcare, such as Australia, it is possible that those who use more primary care services prior to the end of life might also use more care at the end of life. Therefore, this study investigated the relationship between healthcare expenditures in the last 6 months of life and use of general practitioner (GP) services in the 18-7 months before death, using data from a large cohort of older residents of New South Wales (NSW), Australia.

\section{METHODS}

\section{Participants}

This analysis was nested within the Assessing Preventable Hospitalisation InDicators (APHID) study. ${ }^{7}$ APHID uses linked survey and administrative data for participants in the Sax Institute's 45 and Up Study, a prospective cohort of 266950 men and women aged 45 years and over, and residents in NSW, Australia. ${ }^{8}$ Participants entered the study by completing a mailed self-administered questionnaire at study entry (between February 2006 and April 2009), and providing written consent for long-term follow-up and linkage of their health information to a range of routine health databases. People residing in nonurban areas, and those aged 80 years and over, were oversampled. The overall response rate for the 45 and Up Study was estimated to be $18 \%$, and the study included about $10 \%$ of the NSW population aged 45 years and over.

\section{Data sources}

NSW Registry of Births, Deaths and Marriages

The NSW Registry of Births, Deaths and Marriages (RBDM) captures details of all deaths registered in NSW. In this analysis, we used death registrations for participants in the 45 and Up Study who died, up to 31 December 2011. Cause of death was not available at the time of this analysis.

\section{NSW Admitted Patient Data Collection}

The Admitted Patient Data Collection (APDC) is a routinely collected census of hospital separations (discharges, transfers and deaths) from all NSW public and private sector hospitals and day procedure centres. The APDC data used in this analysis related to all separations for the 45 and Up Study participants in the last 6 months of life (hereafter referred to as 'end of life'). ${ }^{6}$

\section{NSW Emergency Department Data Collection}

The Emergency Department Data Collection (EDDC) provides information about patient presentations to the emergency departments (ED) of urban and large regional public hospitals across NSW which cover almost $90 \%$ of all ED visits in the state. Data used in this analysis were those presentations for the 45 and Up Study participants in the end of life.

\section{Medicare and Pharmaceutical Benefits Scheme}

Medicare is the country's universal health insurance scheme and administers claims for subsidised medical care including GP consultations under the Medical Benefits Schedule (MBS) and for pharmaceutical products under the Pharmaceutical Benefits Scheme (PBS). Only services attracting subsidy are included in Medicare data. Dental care, many allied health services and prescription medicines that cost less than specific copayment thresholds are not captured.

'GP visits' were identified as all unreferred attendances by GPs, medical practitioners or practice nurses (on behalf of a medical practitioner) in the 187 months prior to death. This included general consultations (at consultation rooms or residential aged care facilities, in working or after hours), telehealth, management of chronic diseases, and selected psychological services. ${ }^{9}{ }^{10}$ Quintiles of GP visits were generated based on the distribution of GP visits for all participants in the 18-7 months before death. All data from the MBS and PBS, except for claims of in-hospital services in the MBS, were used to calculate expenditures for outpatient healthcare and pharmaceutical services in the last 6 months of life. MBS services were further categorised into 'Specialist' services based on broad type of service item codes. ${ }^{11}$

\section{Data linkage}

Linkage of RBDM and APDC data was performed by the Centre for Health Record Linkage (CHeReL) (http:// www.cherel.org.au) using probabilistic record linkage methods and commercially available software (ChoiceMaker; ChoiceMaker Technologies Inc). CHeReL quality assurance data show false-positive and false-negative rates for data linkage of $0.4 \%$ and $<0.1 \%$, respectively. Linkage of MBS and PBS data was performed by the Sax Institute, using a unique identifying number that was provided to the Commonwealth Department of Human Services.

\section{Eligibility criteria}

The 45 and Up Study participants who died $<12$ months after study entry were excluded from the analysis to ensure that baseline data reflected health prior to, rather than during, the end-of-life period. Moreover, participants who held a Department of Veterans' Affairs (DVA) healthcare card were excluded, because Medicare data does not capture all services provided to these cardholders. Those having no claims to the Medicare system during the entire linkage (from June 2004 to December 2011) were also excluded.

\section{Variables}

Sociodemographic and health characteristics of participants were derived from the self-reported baseline 
questionnaire of the 45 and Up Study (available at https://www.saxinstitute.org.au/our-work/45-up-study/). These included age, sex, educational level, language spoken at home, health insurance status and annual household income. Health characteristics collected included self-reported health status, level of functional limitation, ${ }^{12}$ level of psychological distress, ${ }^{13}$ and number of comorbidities (heart disease, high blood pressure, stroke, diabetes, blood clot, asthma, Parkinson's disease and any cancer except skin cancer). Geographic area of residence was classified according to Statistical Local Areas (SLAs) ${ }^{14}$ defined using boundaries from the 2006 Australian Census.

\section{Outcomes}

The outcomes examined, all for the last 6 months of life, were (1) hospital costs for all inpatient services including hospital costs for 'preventable' hospitalisations (see online supplementary table S1) (classified using the International Statistical Classification of Diseases and Related Health Problems, Tenth Revision, Australian Modification diagnosis codes specified in the 2012 Australian National Healthcare Agreement indicator 'Selected potentially preventable hospitalisation'); ${ }^{15}$ (2) total ED costs; (3) total MBS costs, including costs for GP and specialist consultations; (4) total PBS costs and (5) total costs, the sum of (1)-(4). Hospital costs were assigned to each inpatient episode using the Australian Refined Diagnosis-Related Group-specific average cost reported in the National Hospital Cost Data Collection ${ }^{16}$ for the specific year of admission. Cost for each ED presentation was estimated using visit type, triage category and separation mode. ${ }^{17}$ Costs for MBS and PBS were the sum of all subsidies paid by Medicare for each decedent. All expenditures were converted to 2012 Australian dollars using the consumer price index (CPI) for all groups. ${ }^{18}$

\section{Statistical analysis}

Sociodemographic and health characteristics of decedents were summarised using simple descriptive statistics and compared across quintiles of GP use using Pearson's $\chi^{2}$ statistics. Differences in the average of health service use including number of admissions, ED presentations, number of claims and bed days, number of MBS services and all PBS items in the last 6 months of life by quintile of GP visits in the 18-7 months before death was tested using the non-parametric Wilcoxon-Mann-Whitney tests. Mean total healthcare costs, and separate costs for all hospitalisations including preventable hospitalisations, ED presentations, MBS and PBS, were estimated using generalised linear mixed models with a log link and gamma distribution. A sensitivity analysis was used to test if there was an association between quintile of GP visits in the 18-7 months before death and number of claims, or MBS cost provided for each GP visit in the last 6 months of life. Furthermore, to explore the potential impacts of changes in health status after baseline, a sensitivity analysis was performed restricted to decedents who died between 12 and 24 months after study entry.

The covariates included in the models for estimating healthcare costs were age at death, sex, educational level, language other than English spoken at home, private health insurance, annual household income, selfreported health status, functional limitation, psychological distress and number of comorbidities. Participants were clustered within geographic areas using a random intercept across the SLA of residence $(\mathrm{N}=192)$.

To investigate the effects of baseline health status on healthcare expenditures in the 6 months before death, stratified analyses according to number of comorbidities (none, 1, 2 and more than 3) and self-reported health status (excellent/very good/good vs fair/poor) were performed. Stratified analysis according to age at death ( $<75$ vs $\geq 75$ years) was performed to examine whether the relationship between GP use and costs varied with age.

Stata statistical software (V.12.2, StataCorp LP) with gllamm package ${ }^{19}{ }^{20}$ was used to perform multivariate analyses of cost and quintiles of GP services utilisation; and SAS statistical software (V.9.3, SAS Institute Inc) for all other analyses. All analyses tests were two-sided, and $\mathrm{p}$ value $<0.05$ was considered statistically significant.

\section{RESULTS}

\section{Characteristics of decedent participants}

The analysis included 14819 participants in the 45 and Up Study who died during follow-up, after excluding those who were holders of a DVA healthcare card $(\mathrm{N}=1271)$, died $<12$ months after study entry $(\mathrm{N}=2106)$, or had possibly inconsistent linkage $(\mathrm{N}=120)$. Average follow-up time from study entry to death for decedents in this cohort was approximately 3.6 years (range 17.8 years). The average age at study entry and death was 76 years (range 45-106) and 79 years (range 45108 years), respectively. Women comprised $40 \%$ of total decedents.

Decedents had, on average, 6.4 GP visits (median 4, range $0-137)$ in the 18-7 months before death. In this period, $22 \%$ of decedents had no GP visit, $14 \%$ had $1-2$ visits, $21 \%$ had $3-5$ visits, $22 \%$ had $6-10$ visits and $20 \%$ had more than 10 visits. Decedents in the upper quintile of GP visits were significantly older, were more likely to report poor health status, and had higher levels of functional limitation at baseline (table 1) compared to decedents in the bottom quintile. There were no associations between other sociodemographic or health characteristics and different groups of GP use (table 1).

In this decedent cohort, there were a total of 39008 hospital admissions for any cause in the last 6 months of life, of which 5198 (13\%) were classified as preventable hospitalisations. On average, each decedent had 2.6 hospital admissions (median 2) during the 6 months before death and 0.35 preventable hospitalisations (median 0 ) 
Table 1 Baseline characteristics of decedents by quintile of GP visits in the 18-7 months before death

\begin{tabular}{|c|c|c|c|c|c|c|}
\hline & \multirow{2}{*}{$\begin{array}{l}\text { Total decedent } \\
\text { cohort }\end{array}$} & \multicolumn{5}{|c|}{ Quintile of GP visits } \\
\hline & & 0 & $1-2$ & $3-5$ & $6-10$ & $11+$ \\
\hline $\mathrm{N}$ & 14819 & 3282 (22.2) & $2139(14.4)$ & $3130(21.1)$ & 3246 (21.9) & $3022(20.4)$ \\
\hline \multicolumn{7}{|l|}{ Age at death (years) } \\
\hline $45-54$ & $371(2.5)$ & $63(1.9)$ & $56(2.6)$ & $90(2.9)$ & $85(2.6)$ & $77(2.5)$ \\
\hline $55-64$ & $1363(9.2)$ & $261(8.0)$ & 198 (9.3) & $311(9.9)$ & 307 (9.5) & $286(9.5)$ \\
\hline $65-74$ & 2771 (18.7) & $594(18.1)$ & 398 (18.6) & $580(18.5)$ & $614(18.9)$ & $585(19.4)$ \\
\hline $75-84$ & $5135(34.7)$ & $1031(31.4)$ & $762(35.6)$ & $1119(35.8)$ & $1151(35.5)$ & 1072 (35.5) \\
\hline $85+$ & $5179(34.9)$ & $1333(40.6)$ & 725 (33.9) & $1030(32.9)$ & 1089 (33.5) & 1002 (33.2) \\
\hline p Value & & ref & $<0.001$ & $<0.001$ & $<0.001$ & $<0.001$ \\
\hline \multicolumn{7}{|l|}{ Sex } \\
\hline Male & 8875 (59.9) & 1922 (58.6) & 1299 (60.7) & 1877 (60.0) & $1961(60.4)$ & $1816(60.1)$ \\
\hline Female & $5944(40.1)$ & $1360(41.4)$ & 840 (39.3) & $1253(40.0)$ & 1285 (39.6) & 1206 (39.9) \\
\hline p Value & & ref & 0.11 & 0.25 & 0.13 & 0.22 \\
\hline \multicolumn{7}{|l|}{ Language } \\
\hline English & $13290(89.7)$ & 2946 (89.8) & 1917 (89.6) & 2809 (89.7) & 2904 (89.5) & 2714 (89.8) \\
\hline Other & $1527(10.3)$ & 335 (10.2) & $221(10.3)$ & $321(10.3)$ & $342(10.5)$ & 308 (10.2) \\
\hline Missing & $2(0.0)$ & $1(0.0)$ & $1(0.0)$ & $0(0.0)$ & $0(0.0)$ & $0(0.0)$ \\
\hline p Value & & ref & 0.88 & 0.95 & 0.67 & 0.98 \\
\hline \multicolumn{7}{|l|}{ Education } \\
\hline Did not complete high school & 6418 (43.3) & $1416(43.1)$ & $932(43.6)$ & $1360(43.5)$ & $1420(43.7)$ & $1290(42.7)$ \\
\hline High school/apprenticeship & 5817 (39.3) & $1278(38.9)$ & $847(39.6)$ & $1236(39.5)$ & $1267(39.0)$ & 1189 (39.3) \\
\hline University or higher & $1997(13.5)$ & 465 (14.2) & $278(13.0)$ & 416 (13.3) & 429 (13.2) & 409 (13.5) \\
\hline Missing & $587(4.0)$ & $123(3.7)$ & $82(3.8)$ & $118(3.8)$ & $130(4.0)$ & $134(4.4)$ \\
\hline p Value & & ref & 0.47 & 0.59 & 0.55 & 0.77 \\
\hline \multicolumn{7}{|l|}{ Remoteness } \\
\hline Major cities & $7345(49.6)$ & $1650(50.3)$ & $1062(49.6)$ & $1555(49.7)$ & $1615(49.8)$ & $1463(48.4)$ \\
\hline Inner regional & 4780 (32.3) & $1044(31.8)$ & 710 (33.2) & $1000(31.9)$ & $1051(32.4)$ & 975 (32.3) \\
\hline Outer regional & $2433(16.4)$ & $541(16.5)$ & $343(16.0)$ & $516(16.5)$ & 508 (15.7) & 525 (17.4) \\
\hline Remote/very remote & $257(1.7)$ & $46(1.4)$ & $24(1.1)$ & $57(1.8)$ & $72(2.2)$ & $58(1.9)$ \\
\hline Missing & $4(0.0)$ & $1(0.0)$ & $0(0.0)$ & $2(0.1)$ & $0(0.0)$ & $1(0.0)$ \\
\hline p Value & & ref & 0.61 & 0.60 & 0.07 & 0.21 \\
\hline \multicolumn{7}{|l|}{ Private health insurance } \\
\hline Private extras & $5277(35.6)$ & $1204(36.7)$ & 765 (35.8) & $1093(34.9)$ & $1158(35.7)$ & $1057(35.0)$ \\
\hline Private no extras & 2093 (14.1) & 455 (13.9) & 319 (14.9) & 434 (13.9) & 448 (13.8) & 437 (14.5) \\
\hline Healthcare card & $5092(34.4)$ & 1087 (33.1) & 713 (33.3) & $1092(34.9)$ & $1134(34.9)$ & 1066 (35.3) \\
\hline None & 2357 (15.9) & $536(16.3)$ & $342(16.0)$ & $511(16.3)$ & $506(15.6)$ & $462(15.3)$ \\
\hline $\mathrm{p}$ Value & & ref & 0.70 & 0.41 & 0.46 & 0.18 \\
\hline \multicolumn{7}{|l|}{ Household annual income (\$A) } \\
\hline$<10000$ & $1553(10.5)$ & $313(9.5)$ & $226(10.6)$ & $331(10.6)$ & 345 (10.6) & 338 (11.2) \\
\hline $10000-29999$ & $5612(37.9)$ & $1236(37.7)$ & $827(38.7)$ & $1176(37.6)$ & $1241(38.2)$ & $1132(37.5)$ \\
\hline $30000-49999$ & $1620(10.9)$ & 400 (12.2) & $217(10.1)$ & $344(11.0)$ & $351(10.8)$ & 308 (10.2) \\
\hline $50000-69999$ & $728(4.9)$ & $162(4.9)$ & $98(4.6)$ & $171(5.5)$ & $137(4.2)$ & $160(5.3)$ \\
\hline 70000 or more & $978(6.6)$ & $210(6.4)$ & $153(7.2)$ & $196(6.3)$ & $215(6.6)$ & $204(6.8)$ \\
\hline Prefer not to answer & 2705 (18.3) & $610(18.6)$ & $392(18.3)$ & $574(18.3)$ & $589(18.1)$ & $540(17.9)$ \\
\hline Missing & $1623(11.0)$ & $351(10.7)$ & $226(10.6)$ & $338(10.8)$ & 368 (11.3) & 340 (11.3) \\
\hline $\mathrm{p}$ Value & & ref & 0.16 & 0.46 & 0.24 & 0.06 \\
\hline \multicolumn{7}{|l|}{ Self-reported health status } \\
\hline Excellent & 701 (4.7) & $164(5.0)$ & $76(3.6)$ & $157(5.0)$ & $162(5.0)$ & $142(4.7)$ \\
\hline Very good & 2856 (19.3) & 687 (20.9) & $429(20.1)$ & 570 (18.2) & 649 (20.0) & $521(17.2)$ \\
\hline Good & $5243(35.4)$ & $1252(38.1)$ & $768(35.9)$ & $1095(35.0)$ & $1060(32.7)$ & 1068 (35.3) \\
\hline Fair & 3879 (26.2) & $787(24.0)$ & $557(26.0)$ & $853(27.3)$ & $881(27.1)$ & $801(26.5)$ \\
\hline Poor & $1183(8.0)$ & $211(6.4)$ & $159(7.4)$ & $257(8.2)$ & $274(8.4)$ & $282(9.3)$ \\
\hline Missing & 957 (6.5) & $181(5.5)$ & $150(7.0)$ & $198(6.3)$ & $220(6.8)$ & $208(6.9)$ \\
\hline $\mathrm{p}$ Value & & ref & 0.02 & $<0.001$ & $<0.001$ & $<0.001$ \\
\hline \multicolumn{7}{|l|}{ Number of comorbidities } \\
\hline None & 2857 (19.3) & $660(20.1)$ & $400(18.7)$ & $599(19.1)$ & 623 (19.2) & 575 (19.0) \\
\hline 1 & 4853 (32.7) & 1097 (33.4) & 700 (32.7) & $1044(33.4)$ & 1062 (32.7) & $950(31.4)$ \\
\hline
\end{tabular}


Table 1 Continued

\begin{tabular}{|c|c|c|c|c|c|c|}
\hline & \multirow[b]{2}{*}{$\begin{array}{l}\text { Total decedent } \\
\text { cohort }\end{array}$} & \multicolumn{5}{|c|}{ Quintile of GP visits } \\
\hline & & 0 & $1-2$ & $3-5$ & $6-10$ & $11+$ \\
\hline 2 & $4122(27.8)$ & $878(26.8)$ & $595(27.8)$ & $842(26.9)$ & 918 (28.3) & $889(29.4)$ \\
\hline 3 or more & 2987 (20.2) & 647 (19.7) & $444(20.8)$ & $645(20.6)$ & $643(19.8)$ & $608(20.1)$ \\
\hline $\mathrm{p}$ Value & & ref & 0.43 & 0.70 & 0.51 & 0.07 \\
\hline \multicolumn{7}{|l|}{ Functional limitation } \\
\hline No limitation & $1305(8.8)$ & $322(9.8)$ & $201(9.4)$ & $273(8.7)$ & $285(8.8)$ & $224(7.4)$ \\
\hline Minor limitation & $942(6.4)$ & 217 (6.6) & $135(6.3)$ & $184(5.9)$ & $221(6.8)$ & $185(6.1)$ \\
\hline Mild limitation & $1748(11.8)$ & 410 (12.5) & $259(12.1)$ & 388 (12.4) & $378(11.6)$ & $313(10.4)$ \\
\hline Moderate limitation & 2890 (19.5) & $672(20.5)$ & $414(19.4)$ & 573 (18.3) & 625 (19.3) & $606(20.1)$ \\
\hline Severe limitation & 5867 (39.6) & $1201(36.6)$ & $814(38.1)$ & $1285(41.1)$ & $1289(39.7)$ & 1278 (42.3) \\
\hline Missing & 2067 (13.9) & 460 (14.0) & 316 (14.8) & 427 (13.6) & 448 (13.8) & 416 (13.8) \\
\hline$p$ Value & & ref & 0.73 & 0.004 & 0.08 & $<0.001$ \\
\hline \multicolumn{7}{|l|}{ Psychological distress } \\
\hline Low distress & 10553 (71.2) & 2392 (72.9) & 1535 (71.8) & 2190 (70.0) & 2299 (70.8) & $2137(70.7)$ \\
\hline Moderate distress & 2099 (14.2) & $442(13.5)$ & 284 (13.3) & 467 (14.9) & $455(14.0)$ & 451 (14.9) \\
\hline High distress & $848(5.7)$ & $172(5.2)$ & $118(5.5)$ & $183(5.8)$ & $203(6.3)$ & $172(5.7)$ \\
\hline Very high distress & $386(2.6)$ & $87(2.7)$ & $63(2.9)$ & $85(2.7)$ & 74 (2.3) & 77 (2.5) \\
\hline Missing & $933(6.3)$ & $189(5.8)$ & $139(6.5)$ & $205(6.5)$ & $215(6.6)$ & $185(6.1)$ \\
\hline$p$ Value & & ref & 0.86 & 0.15 & 0.17 & 0.26 \\
\hline
\end{tabular}

Numbers in parenthesis represent the proportion of decedent in the specified quintile. $p$ Values were estimated excluding missing records. GP, general practitioner. Bold values indicate a statistically significant difference at $p<0.05$.

(table 2). Almost $85 \%$ of decedents $(\mathrm{N}=12563)$ had at least one hospitalisation in this period, and $24 \%$ $(\mathrm{N}=3619)$ had at least one preventable hospitalisation, while approximately $75 \%(\mathrm{~N}=11117)$ had at least one presentation to ED. There was a significant increase in the average number of hospital admissions and bed days in the upper quintiles of GP use compared to the lowest for preventable hospitalisations (table 2). By contrast, the average number of ED presentations was higher in the lowest quintile of GP use compared to the other quintiles. There was a strong and positive association between numbers of MBS and PBS claims in the last 6 months of life and quintile of GP visits in the 18-7 months before death (table 2). The positive association was also observed even if we took into account number of claims by number of GP visits in order to capture the intensity of services provided for each visit (data not shown).

\section{Healthcare costs}

Expenditures were right skewed with the mean (median; IQR) for the total healthcare cost in the last 6 months being \$A20 453 (14 835; 6224-27 806). Mean (median, IQR) costs for all hospitalisations, preventable hospitalisations, ED presentation, MBS and PBS in this period for each decedent were \$A18 753 (12 950; 4981-25 805), \$A3151 (0; 0-0), \$A971 (751; 211-1397), \$A415 (83; 0$529)$, and $\$ A 313(0 ; 0-295)$, respectively. The average cost for GP services per person was twice as much as for specialist services (table 3). Expenditure on hospital services accounted for the majority $(79 \%)$ of total healthcare costs in the last 6 months of life, with ED visits
(9\%), MBS claims (8\%) and PBS claims (4\%) making much smaller contributions.

There was no significant trend in the unadjusted or adjusted hospital cost ( $p$ value for trend $=0.14$ or 0.33 , respectively), and cost for preventable hospitalisations ( $\mathrm{p}$ value for trend $=0.42$ or 0.08 , respectively) at the 6 months before death across quintiles of GP visits (table 3 and figure 1). However, there was a significant inverse trend between increasing GP visits and adjusted ED cost ( $p$ value for trend $=0.02$ ), driven by greater use of ED services in the lowest quintile of GP use compared with the other quintiles (table 3 and figure 1). There was a steep increase in MBS and PBS costs according to number of GP visits ( $p$ value for trend $<0.001$ ). Separate analyses for MBS costs for GP consultations, specialist consultations and all other claims showed similar patterns (table 3). The association was also observed for MBS cost per each GP visit. Overall, there was a significant positive association between quintile of GP visits and total healthcare cost, with this result driven by the costs for outpatient services and pharmaceuticals rather than hospital costs.

Stratified analyses according to number of comorbidities and self-reported health status showed no differences between strata or compared to the unstratified results (see online supplementary table S2). Stratified analysis by age at death showed patterns similar to the main analysis, with significant trends of increasing MBS costs with increasing quintiles of GP visits in both age groups, but no significant increase in hospital cost (see online supplementary table S2). Sensitivity analysis restricting to the subset of decedents who died in the 
Table 2 Average usage of healthcare services in the last 6 months of life, by quintile of GP visits in the 18-7 months before death

\begin{tabular}{|c|c|c|c|c|c|c|}
\hline & \multirow{2}{*}{$\begin{array}{l}\text { Average usage } \\
\text { of healthcare } \\
\text { service for the } \\
\text { decedent cohort }\end{array}$} & \multicolumn{5}{|c|}{$\begin{array}{l}\text { Average usage of healthcare service by quintile of GP visit, mean } \\
\text { (median) }\end{array}$} \\
\hline & & 0 & $1-2$ & $3-5$ & $6-10$ & $11+$ \\
\hline \multicolumn{7}{|l|}{ Hospital bed days } \\
\hline $\begin{array}{l}\text { All hospital admissions } \\
\text { p Value }\end{array}$ & $22.02(14)$ & $\begin{array}{l}21.41(13) \\
\text { ref }\end{array}$ & $\begin{array}{l}21.55(14) \\
0.37\end{array}$ & $\begin{array}{l}21.97(14) \\
0.10\end{array}$ & $\begin{array}{l}22.30(15) \\
0.03\end{array}$ & $\begin{array}{l}22.76(14) \\
0.01\end{array}$ \\
\hline $\begin{array}{l}\text { Preventable hospitalisations } \\
\text { p Value }\end{array}$ & $3.21(0)$ & $\begin{array}{l}3.26(0) \\
\text { ref }\end{array}$ & $\begin{array}{l}3.17(0) \\
0.37\end{array}$ & $\begin{array}{l}3.03(0) \\
0.98\end{array}$ & $\begin{array}{l}3.26(0) \\
0.85\end{array}$ & $\begin{array}{l}3.32(0) \\
0.50\end{array}$ \\
\hline \multicolumn{7}{|l|}{ Number of hospital admissions } \\
\hline $\begin{array}{l}\text { All hospital admissions } \\
\text { p Value }\end{array}$ & $2.63(2)$ & $\begin{array}{l}2.53(2) \\
\text { ref }\end{array}$ & $\begin{array}{l}2.49(2) \\
0.28\end{array}$ & $\begin{array}{l}2.65(2) \\
0.04\end{array}$ & $\begin{array}{l}2.58(2) \\
0.04\end{array}$ & $\begin{array}{l}2.88(2) \\
<0.001\end{array}$ \\
\hline $\begin{array}{l}\text { Preventable hospitalisations } \\
\text { p Value }\end{array}$ & $0.35(0)$ & $\begin{array}{l}0.35(0) \\
\text { ref }\end{array}$ & $\begin{array}{l}0.35(0) \\
0.34\end{array}$ & $\begin{array}{l}0.35(0) \\
0.95\end{array}$ & $\begin{array}{l}0.35(0) \\
0.92\end{array}$ & $\begin{array}{l}0.35(0) \\
0.46\end{array}$ \\
\hline $\begin{array}{l}\text { Number of ED presentations } \\
p \text { Value }\end{array}$ & 1.67 (1) & $\begin{array}{l}1.74(1) \\
\text { ref }\end{array}$ & $\begin{array}{l}1.65(1) \\
0.03\end{array}$ & $\begin{array}{l}1.63(1) \\
0.004\end{array}$ & $\begin{array}{l}1.65(1) \\
0.002\end{array}$ & $\begin{array}{l}1.66(1) \\
0.006\end{array}$ \\
\hline \multicolumn{7}{|l|}{ Number of MBS claims } \\
\hline $\begin{array}{l}\text { \#All claims } \\
\text { p Value }\end{array}$ & $7.14(2)$ & $\begin{array}{l}0.45(0) \\
\text { ref }\end{array}$ & $\begin{array}{l}2.93(0) \\
<0.001\end{array}$ & $\begin{aligned} & 5.33(3) \\
< & 0.001\end{aligned}$ & $\begin{aligned} & 9.00(7) \\
< & 0.001\end{aligned}$ & $\begin{array}{l}17.28(14) \\
<0.001\end{array}$ \\
\hline \# GP & $2.52(1)$ & $0.12(0)$ & $0.88(0)$ & $1.74(1)$ & 3.04 (2) & $6.54(6)$ \\
\hline$p$ Value & & ref & $<0.001$ & $<0.001$ & $<0.001$ & $<0.001$ \\
\hline \# Specialist & $0.61(0)$ & $0.03(0)$ & $0.21(0)$ & $0.48(0)$ & $0.80(0)$ & 1.45 (1) \\
\hline p Value & & ref & $<0.001$ & $<0.001$ & $<0.001$ & $<0.001$ \\
\hline \# All other & $4.02(0)$ & $0.30(0)$ & $1.85(0)$ & 3.11 (1) & $5.16(3)$ & $9.29(6)$ \\
\hline Value & & ref & $<0.001$ & $<0.001$ & $<0.001$ & $<0.001$ \\
\hline Number of PBS claims & $6.35(0)$ & $0.16(0)$ & $1.35(0)$ & $3.54(0)$ & $8.02(2)$ & $17.73(13)$ \\
\hline $\mathrm{p}$ Value & & ref & $<0.001$ & $<0.001$ & $<0.001$ & $<0.001$ \\
\hline
\end{tabular}

ED, emergency department; GP, general practitioner; MBS, Medical Benefits Schedule; PBS, Pharmaceutical Benefits Scheme. Bold values indicate a statistically significant difference at $p<0.05$.

12-24 months after study entry ( $\mathrm{n}=2615)$ showed a similar pattern of increasing outpatient healthcare cost with increasing quintiles of GP visits, and no significant association for hospital cost (see online supplementary table S3).

\section{DISCUSSION}

This analysis showed that greater use of GP services in the 18-7 months before death was associated with greater total healthcare costs at the 6 months before death, with this result driven by the costs for outpatient services and pharmaceuticals. There was no association between GP use in the 18-7 months before death and hospital inpatient costs in the last 6 months of life.

These findings, to the best of our knowledge, contrast starkly with results from the only previous study that has directly addressed this issue, in a large sample of US Medicare beneficiaries, ${ }^{6}$ which found an inverse relationship between GP use and total costs. A striking difference between the two studies was probably due to the different patterns of GP use: in this study, $42 \%$ of decedents had at least six GP visits or more in the 187 months before death, compared with only $22 \%$ of the US decedents. ${ }^{6}$ This is, however, consistent with the overall higher number of annual GP visits per capita in
Australia (6.5) versus in the USA (3.9). ${ }^{21}$ Such a large gap in healthcare usage levels may reflect differences in the design, generosity and accessibility of the US and Australian healthcare system, which may explain the discrepant results. In the USA, unlike in Australia, limitations in access to care may mean that patients who would benefit from GP care are not receiving it, exacerbating ill-health in the end-of-life period.

The potential for preventive care to avert end-of-life hospital costs would be expected to be greatest for those admissions that are considered to be preventable through primary care. About $13 \%$ hospitalisations in the last 6 months of life in our analysis met the current Australian definition for a preventable hospitalisation, as used nationally to monitor primary care performance. However, the absence of a relationship between quintile of GP visits and costs, either for all hospital costs or preventable hospitalisations, suggests that if GPs have a role in preventing these hospitalisations, it is likely to lie much earlier in life and in the causal pathways for these conditions, consistent with findings regarding the key roles of patient sociodemographic factors and adverse health-related behaviours. ${ }^{22} 23$

Findings of positive association between GP visits and total costs in this study suggested that hospital care at the end of life could reflect the 'real' need for 
Table 3 Mean healthcare expenditure $(\$ A)$ and its $95 \% \mathrm{Cl}$ in the last 6 months of life, by quintile of GP visits in the $18-7$ months before death

\section{Mean healthcare \\ expenditure $(95 \% \mathrm{Cl})$ \\ for the decedent cohort 0}

Mean healthcare expenditure $(95 \% \mathrm{Cl})$ by quintile of $\mathrm{GP}$ visits

$1-2$

3-5

$6-10$

$11+$

V Value

Total healthcare costs

Unadjusted 20453 (20 439 to 20466$) \quad 19413$ (18 713 to 20 113) $19742(18860$ to 20624$) 20355$ (19 603 to 21 106) 20740 (19 988 to 21492$) \quad 21877$ (21 055 to 22699$)$

Adjusted 20495 (20 427 to 20562$) \quad 19333$ (19 195 to 19 471) 19782 (19615 to 19 948) 20314 (20 175 to 20 453) 20891 (20 751 to 21030$) \quad 22022(21867$ to 22177$)$

All hospital admissions

Unadjusted 18753 (18 749 to 18757$) \quad 18363(17658$ to 19068$) \quad 18535(17654$ to 19416$) \quad 18893(18150$ to 19635$) \quad 18811(18085$ to 19537$) \quad 19124(18359$ to -19889$) \quad 0.14$

Adjusted $18792(18728$ to 18 856) $18303(18165$ to 18441) $18585(18420$ to 18750) $18857(18721$ to 18993$) \quad 18956(18823$ to 19090$) \quad 19226(19084$ to 19369$)$

Preventable hospitalisation

All ED presentations

Unadjusted 971 (971 to 972 )

Adjusted $\quad 973$ (970 to 975 )

All MBS claims

Unadjusted $\quad 415(410$ to 421$)$

Adjusted

GP MBS claims

Unadjusted $124(123$ to 126$)$

Adjusted 127 (125 to 129)

$$
3224 \text { (2911 to 3537) }
$$

3302 (3242 to 3361 )

1017 (982 to 1051)

1018 (1013 to 1024)

24.4 (21.8 to 27.1$)$

22.5 (22.4 to 22.7 )

6.5 (5.9 to 7.1$)$

6.1 (6.1 to 6.2$)$

3.2 (2.7 to 3.7$)$

2.6 (2.6 to 2.6$)$

$\begin{array}{ll}\text { Unadjusted } & 65.2 \text { (64.4 to } 66.0) \\ \text { Adjusted } & 69.9 \text { (68.9 to } 71.0)\end{array}$

All other MBS claims

Unadjusted 226 (223 to 229)

Adjusted

235 (232 to 238 )

Unadjusted 313 (308 to 318 )

Adjusted

(308 to 318 )

14.7 (12.7 to 16.8$)$

13.3 (13.2 to 13.4 )

$8.3(6.7$ to 10.0$)$

7.4 (7.3 to 7.4 )
3281 (2887 to 3676 )

3242 (3166 to 3319 )

952 (912 to 992)

951 (945 to 957)

171 (149 to 195$)$

173 (172 to 175$)$

47.3 (41.7 to 52.9$)$

47.5 (47.1 to 47.8 )

25.5 (20.2 to 30.7$)$ 26.2 (25.9 to 26.6$)$

98.8 (81.9 to 115.7$)$

99.8 (98.8 to 100.8 )

83.1 (62.5 to 103.7 ) 85.2 (84.0 to 86.3)
3083 (2777 to 3390 )

3160 (3102 to 3218 )

951 (918 to 984)

951 (946 to 957)

318 (283 to 353 )

327 (325 to 330 )

87.6 (79.0 to 96.2$)$

88.8 (88.2 to 89.5 )

55.6 (46.1 to 65.1$)$ 58.6 (57.9 to 59.3$)$

175 (150 to 199$)$

183 (182 to 185 )

193 (154 to 233) 201 (199 to 204)
3121 (2817 to 3426 )

3160 (3104 to 3215 )

961 (928 to 994)

964 (958 to 969)

531 (473 to 589 )

542 (538 to 546 )

152 (137 to 167$)$

154 (153 to 155$)$

86.7 (72.2 to 101.2)

94.6 (93.5 to 95.7 )

293 (252 to 333 )

300 (298 to 303 )

437 (349 to 525$)$ 452 (447 to 457 )
3082 (2771 to 3394$) \quad 0.42$

3096 (3039 to 3154) $\quad 0.08$

967 (933 to 1002) $\quad 0.06$

971 (965 to 977)

988 (876 to 1099)

1030 (1022 to 1038$)$

315 (283 to 346 )

325 (322 to 327 )

148 (122 to 173$)$

159 (157 to 161$)$

525 (450 to 601 )

555 (550 to 559$)$

798 (631 to 964$)$ 845 (835 to 855 )

Values were adjusted mean of costs either unadjusted or adjusted for age at death (10-year groups), sex, language, education, private health insurance, number of comorbidities, self-reported health status, functional limitation, psychological distress and random effect of statis

ED, emergency department; MBS, Medical Benefits Schedule; PBS, Pharmaceutical Benefits Scheme. 
Figure 1 Adjusted* mean healthcare expenditures in the last 6 months of life, by quintile of GP visits in the 18-7 months before death. *Adjusted for age at death (10-year groups), sex, language, education, private health insurance, number of comorbidities, self-reported health status, functional limitation, psychological distress and random effect of statistical local area. AUD, Australian dollar; GP, general practitioner; MBS, Medical Benefits Schedule; PBS, Pharmaceutical Benefits Scheme.

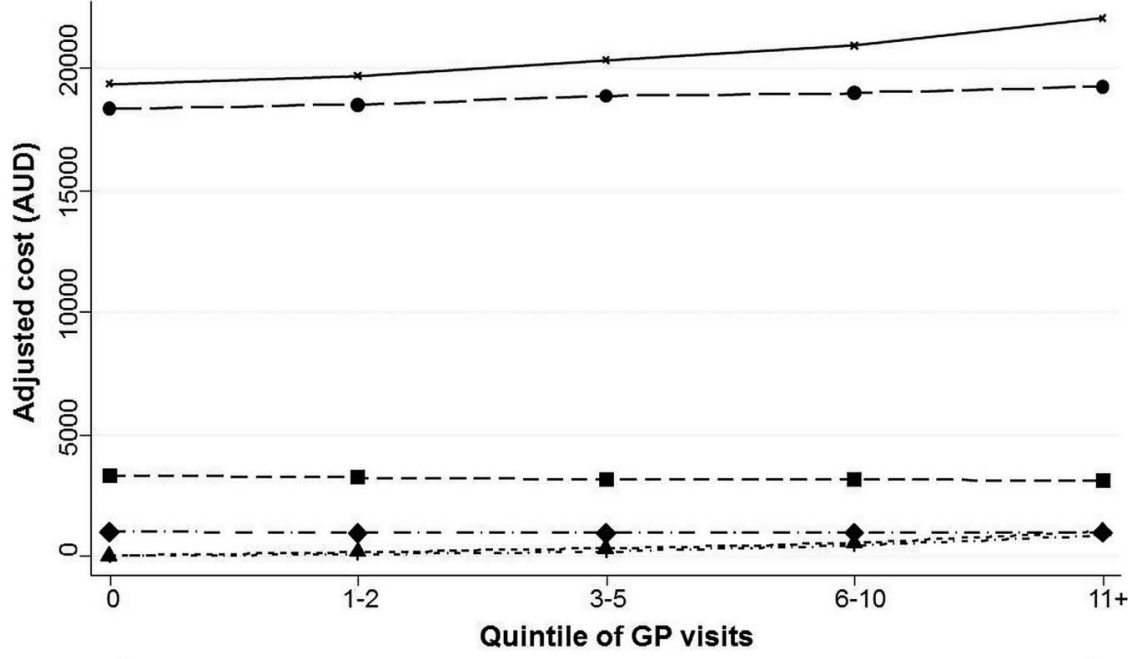

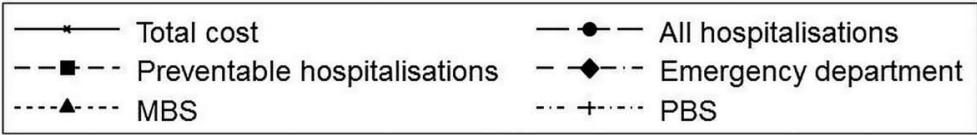

multidisciplinary care for those with deteriorating health and high risk of mortality, rather than admissions that could be avoided. Thus, where preventable hospitalisation is used as a performance indicator for primary care, it may be appropriate to consider excluding admissions at the end of life.

There was no existing study of the relationship between GP visits and ED cost at the end of life with which to compare with our results. We could find only one study for patients with cancer at the end of life suggesting that a greater level of continuity of care with their primary care provider was associated with fewer presentations to ED and thus lower cost. ${ }^{24}$ We found that decedents who used no GP services in the lead up to end of life had more ED visits at the end of life. These decedents, who were older on average than others, may have included a greater proportion of residents of residential aged care, for whom there is growing concern that current delivery of GP services is not optimal. $^{25}$

Greater usage of GP services in the 18-7 months before death was associated with higher use of pharmaceutical and outpatient services, including GP and specialist visits, in the last 6 months of life. This association is consistent with patterns of healthcare expenditure in the general population. ${ }^{26}$ Only $53 \%$ of decedents in this cohort visited their GP in the last 6 months of life period, compared with $75 \%$ who had at least one ED presentation and $85 \%$ who had at least one hospital admission. These findings reflect the current predominant organisation of end-of-life care in Australia, where $54 \%$ of people die in hospital. ${ }^{27}$

Indeed, although most Australians express a wish to die at home, few do so. ${ }^{27}$ Only about $15 \%$ of Australians aged 65 years and over die at home, compared with about $30 \%$ in countries including New Zealand, the USA, Ireland and France. ${ }^{28}$ International studies have indicated that home-based palliative care for those at the end of life is effective in delivering better outcomes including increased patient satisfaction and lower costs, ${ }^{29} 30$ and there is substantial potential to further develop these models of care in Australia.

This study had several strengths. It used detailed questionnaire data from a large prospective cohort study, with comprehensive ascertainment of healthcare utilisation and costs from administrative databases, eliminating the potential for recall bias. While previous Australian studies of end-of-life healthcare costs have reported only hospital costs, ${ }^{3} 3132$ this study captured inpatient, ED, outpatient services and pharmaceuticals costs. Nonetheless, only Medicare-subsidised outpatient expenditures were included, and costs for non-admitted community-based services, such as home-based palliative care not provided by GPs, or dispensing of non-subsided pharmaceuticals, were not captured. This might reduce the generalisability of the findings to other populations with different healthcare systems. In addition, the incompleteness of data collection for presentations to all EDs in NSW may have resulted in underestimation of ED costs. Moreover, measures of comorbidities and health status used baseline questionnaire data, so did not reflect incident conditions or deteriorating health during follow-up.

This study was restricted to decedent participants of the 45 and Up Study, raising a concern regarding the generalisability of these findings to other populations. The 45 and Up Study had a low response rate (18\%), reflecting the trend towards declining participation rates in cohort and other epidemiological studies such as the UK Biobank (5-10\%), a comparable study focussing on achieving a large, diverse cohort of participants. ${ }^{33}$ However, relative risk estimates from the 45 and Up Study have been shown to be comparable with those from population health surveys, ${ }^{34}$ and the large sample 
size provides substantial heterogeneity to support valid within-cohort comparisons.

The association between GP visits in the 18-7 months before death and use of healthcare services in the following 6 months is likely to reflect the influences of health seeking behaviour and access to healthcare, as well as need for healthcare. Although these factors could not be fully partitioned out in the current analyses, they did control for positive health behaviours (a proxy measure of health seeking behaviour) and clustering by geographic area (a surrogate for access to care).

This study found that in the Australian setting, greater use of GP services in the lead up to end of life had no impact on hospital costs in the 6-month end-of-life period, but was associated with higher costs for outpatient services, pharmaceuticals and overall total healthcare cost. There was some indication that limited GP access might increase ED use at end of life. The findings do not preclude a key role for GP care in containing end-of-life costs, for example, through discussion of end-of life treatment preferences and advance care planning, delivering care in residential aged-care settings, and participating in home-based palliative care.

Acknowledgements The APHID investigator team comprises Louisa Jorm, Alastair Leyland, Fiona Blyth, Robert Elliot, Kirsty Douglas, Sally Redman, Marjon van der Pol, Michael Falster, Bich Tran, Neville Board, Danielle Butler, Douglas Lincoln, Sanja Lujic, Damilola Olajide, Deborah Randall, Kim Sutherland and Diane Watson. This research was completed using data collected through the 45 and Up Study (http://www.saxinstitute.org.au). The 45 and Up Study is managed by the Sax Institute in collaboration with major partner Cancer Council NSW; and partners: the National Heart Foundation of Australia (NSW Division); NSW Ministry of Health; beyondblue; NSW Government Family \& Community Services-Carers, Ageing and Disability Inclusion; and the Australian Red Cross Blood Service. We thank the many thousands of people participating in the 45 and Up Study.

Contributors BT conducted the data analyses and drafted the manuscript. MOF extracted data for analysis, assisted with statistical methods and data presentation, reviewed and edited the manuscript. FG advised on the statistical methods, assisted with data interpretation and edited the manuscript. LJ conceived, designed and managed the study, obtained funding, reviewed and edited the manuscript and provided overall supervision. BT, MOF and LJ have full access to the data. All authors reviewed and approved the final manuscript.

Funding The study was funded by a National Health and Medical Research Council Partnership Project Grant (\#1036858) and by partner agencies the Australian Commission on Safety and Quality in Health Care, the Agency for Clinical Innovation and the NSW Bureau of Health Information.

Competing interests None declared.

Patient consent Obtained.

Ethics approval Ethics approval for the APHID study was obtained from the NSW Population and Health Services Research Ethics Committee, Aboriginal Health and Medical Research Council of NSW Ethics Committee, and the University of Western Sydney Ethics Committee. The conduct of the 45 and Up Study was approved by the University of New South Wales Human Research Ethics Committee.

Provenance and peer review Not commissioned; externally peer reviewed. Data sharing statement No additional data are available.

Open Access This is an Open Access article distributed in accordance with the Creative Commons Attribution Non Commercial (CC BY-NC 4.0) license, which permits others to distribute, remix, adapt, build upon this work noncommercially, and license their derivative works on different terms, provided the original work is properly cited and the use is non-commercial. See: http:// creativecommons.org/licenses/by-nc/4.0/

\section{REFERENCES}

1. Lubitz JD, Riley GF. Trends in Medicare payments in the last year of life. N Engl J Med 1993;328:1092-6.

2. Stooker T, van Acht JW, van Barneveld EM, et al. Costs in the last year of life in the Netherlands. Inquiry 2001;38:73-80.

3. Kardamanidis K, Lim K, Da Cunha C, et al. Hospital costs of older people in New South Wales in the last year of life. Med J Aust 2007;187:383-6.

4. Lubitz J, Prihoda R. The use and costs of Medicare services in the last 2 years of life. Health Care Financ Rev 1984;5:117-31.

5. Rosenwax LK, McNamara BA, Murray K, et al. Hospital and emergency department use in the last year of life: a baseline for future modifications to end-of-life care. Med J Aust 2011;194:570-3.

6. Kronman AC, Ash AS, Freund KM, et al. Can primary care visits reduce hospital utilization among Medicare beneficiaries at the end of life? J Gen Intern Med 2008;23:1330-5.

7. Jorm LR, Leyland AH, Blyth FM, et al. Assessing Preventable Hospitalisation InDicators (APHID): protocol for a data-linkage study using cohort study and administrative data. BMJ Open 2012;2:pii: e002344.

8. Banks E, Redman S, Jorm L, et al. Cohort profile: the 45 and up study. Int J Epidemiol 2008;37:941-7.

9. METeOR. Service event-General Practitioner (GP) service, total number NN[N]. METeOR identifier 593673. National Health Performance Authority, Standard 11/12/2014. http://meteor.aihw.gov. au/content/index.phtml/itemld/593673

10. Mapping of Medicare items to Broad Type of Service; Medicare Australia Statistics, Department of Human Services, Australian Government. http://medicarestatistics.humanservices.gov.au/ statistics/do.jsp?_PROGRAM=/statistics/std_btos_map\&start_ $\mathrm{dt}=0$ \&end $\mathrm{dt}=0$

11. Medicare Australia Statistics. Appendix 2: mapping of Medicare items to broad type of service. Australian Goverment, Department of Human Services. Last updated 25 March 2015. http:// medicarestatistics.humanservices.gov.au/statistics/do.jsp? PROGRAM=/statistics/std_btos_map\&start_dt=0\&end_dt=0

12. Stewart A, Kamberg CJ. Physical functioning measures. In: Steward A, Ware J, eds. Measuring functioning and well-being: the medical outcomes study approach. Durham, NC: Duke University Press, 199281-101.

13. Kessler R, Mroczek D. Final version of our Non-Specific Psychological Distress Scale [memo dated 3/10/94]. Ann Arbor, MI: Survey Research Center of the Institute for Social Research: University of Michigan, 1994.

14. Trewin D. Statistical geography volume 1-Australian Standard Geographical Classification (ASGC). Canberra: Australian Bureau of Statistics, ABS, Catalogue No. 1216.0, 2006.

15. National Healthcare Agreement. PI 22-Selected potentially preventable hospitalisations. Australian Institute of Health and Welfare, 2012. http://meteor.aihw.gov.au/content/index.phtml/itemld/ 443687

16. National Hospital Cost Data Collection. The Department of Health. Australia Government. http://www.health.gov.au/

17. Costs of Care Standards 2009/10. NSW Department of Health. Document Number GL2011_007. File Number H11/22988. http:// www0.health.nsw.gov.au/policies/gl/2011/pdf/gl2011_007.pdf

18. Australian Bureau of Statistics. ABS 6401.0 Tables 1\&2, series A2325846C. June 2013. http://www.abs.gov.au/AUSSTATS/abs@ nsf/DetailsPage/6401.0Jun\%202013?OpenDocument

19. Rabe-Hesketh S, Skrondal A, Pickles A. Maximum likelihood estimation of limited and discrete dependent variable models with nested random effects. J Econ 2005;128:301-23.

20. Rabe-Hesketh S, Skrondal A, Pickles A. Generalized multilevel structural equation modelling. Psychometrika 2004;69:167-90.

21. Thomson S, Osborn R, Squires D, et al. International profiles of health care systems. The Commonwealth Fund, 2011.

22. Tran B, Falster MO, Douglas $\mathrm{K}$, et al. Health behaviours and potentially preventable hospitalisation: a prospective study of older Australian adults. PLOS ONE 2014;9:e93111.

23. Falster MO, Jorm LR, Douglas KA, et al. Sociodemographic and health characteristics, rather than primary care supply, are major drivers of geographic variation in preventable hospitalizations in Australia. Med Care 2015;53:436-45. 
24. Burge F, Lawson B, Johnston G. Family physician continuity of care and emergency department use in end-of-life cancer care. Med Care 2003;41:992-1001.

25. Hillen JB, Reed RL, Woodman RJ, et al. Hospital admissions from residential aged care facilities to a major public hospital in South Australia (1999-2005). Australas J Ageing 2011;30:202-7.

26. National Health Performance Authority. Healthy Communities: Frequent GP attenders and their use of health services in 2012-13. 2015. http://www.myhealthycommunities.gov.au/Content/ publications/downloads/NHPA_HC_Frequent_GP_attenders Report_March_2015.pdf

27. Swerissen H, Duckett S. Dying well. Grattan Institute, 2014. ISBN: 978-1-925015-61-4. http://grattan.edu.au/wp-content/uploads/2014/ 09/815-dying-well.pdf

28. Broad JB, Gott M, Kim H, et al. Where do people die? An international comparison of the percentage of deaths occurring in hospital and residential aged care settings in 45 populations, using published and available statistics. Int J Public Health 2013;58:257-67.
29. Brumley R, Enguidanos S, Jamison P, et al. Increased satisfaction with care and lower costs: results of a randomized trial of in-home palliative care. J Am Geriatr Soc 2007;55:993-1000.

30. Brumley RD, Enguidanos S, Cherin DA. Effectiveness of a home-based palliative care program for end-of-life. J Palliat Med 2003;6:715-24.

31. Moorin RE, Holman CD. The cost of in-patient care in Western Australia in the last years of life: a population-based data linkage study. Health Policy 2008;85:380-90.

32. Calver J, Bulsara M, Boldy D. In-patient hospital use in the last years of life: a Western Australian population-based study. Aust NZ J Public Health 2006;30:143-6.

33. Manolio TA, Weis BK, Cowie CC, et al. New models for large prospective studies: is there a better way? Am J Epidemiol 2012;175:859-66.

34. Mealing NM, Banks E, Jorm LR, et al. Investigation of relative risk estimates from studies of the same population with contrasting response rates and designs. BMC Med Res Methodol 2010; 10:26. 